\title{
perifèria
}

Número 20 (2) diciembre, 2015

revistes.uab.cat/periferia

\section{Algunas ideas sobre la relación entre consumo cultural, capital cultural y creación musical juvenil en la comuna 15 del Distrito Especial de Aguablanca en la ciudad de Cali, Colombia}

\author{
Carlos Andrés Tobar Tovar - Pontificia Universidad Javeriana Cali, Colombia ${ }^{1}$
}

DOI: http://dx.doi.org/10.5565/rev/periferia.468

\section{Resumen}

El siguiente artículo propone una vía de interpretación para la relación entre consumo cultural, capital cultural y creación musical juvenil para el caso de jóvenes habitantes de la comuna 15 en el Distrito Especial de Aguablanca de la ciudad de Cali, Colombia. El trabajo de campo que soporta la discusión categorial se realizó siguiendo las consignas de la Investigación Acción Participativa (IAP) las cuales fomentan un desempeño activo por parte del investigador en los procesos que desarrollan los sujetos que participanen la investigación. En consecuencia se acompañó el grupo en el desarrollo de tres actividades entre enero y diciembre de 2012, éstas conducentes a la formación política, la realización de piezas musicales y audiovisuales, y la implementación de una estrategia para visibilizar el grupo ante la comunidad.

Palabras clave: jóvenes, consumo cultural, capital cultural, creación musical.

\begin{abstract}
The following article proposes an interpretation for the relationship between cultural consumption, capital consumption, and youth musical creation. This article focuses in the young inhabitants from the 15th commune, located in El Distrito Especial de Aguaglanca in Cali city, Colombia. The field work supporting the categorical discussion was done following the ideals of the Participative Action Investigation (PAI), those ideals call for the researcher's active involvement in the processes that subjects participating in the investigation engage with. In consequence, there were three activities in which the researcher accompanied the group from January to December of 2012. Such activities contributed to the group's political formation, as well as the realization of musical and audiovisual pieces, and the implementation of a strategy to place the group at the center of the community.
\end{abstract}

Keywords:youth, cultural consumption, cultural capital, musical creation.

\footnotetext{
${ }^{1}$ Enviar correspondencia a: Carlos Andrés Tobar Tovar catobar@javerianacali.edu.co
} 


\section{perifèria}

Número 20 (2) diciembre, 2015

revistes.uab.cat/periferia

La investigación de la cual se deriva el siguiente artículo fue realizada entre enero y diciembre del año 2012bajo eltítuloProcesos de comunicación y cultura política en la comuna 15 del Distrito Especial de Aguablanca, una investigación de acompañamiento con comunidades de un centro comunitario del oriente caleño. El objetivo de la propuesta consistía en analizar los procesos culturales de participación en la cultura política de un grupo de jóvenes creadores de músicas habitantes del sector.

Los jóvenes que participaron en la investigación integran varios grupos musicales del sector y representan diferentes barrios en los cuales la inseguridad y la violencia hacen partede la cotidianidad. Se consideró que una manera de acceder a las experiencias de vida de los jóvenes músicos podría llevarse a cabo a través de la grabación de piezas de comunicación queayudarana visibilizar las valoraciones que tales jóvenes hacen de la comuna 15.

En este sentido, se asumieron las consignas de la Investigación Acción Participativa (IAP)en virtud de la posibilidad de concebir a los jóvenes como participantes del proceso investigativo y de otorgar un lugar significativos a las actividades conducentes a la producción de material musical. De esta forma, se habilitó el estudio de grabación de audio de la Pontificia Universidad Javeriana Cali para que tres grupos musicales compuestos por 19 jóvenes, entre los 15 y los 23 años de edad,pudiesentener un lugar donde producir sin que tuviesen que pagar por el servicio.

La investigación se realizó en dos escenarios: el primero corresponde al espacio de producciónen el cual los grupos musicales contaron con el apoyo de los estudiantes del Programa de Comunicación de la Universidadpara operar los equipos y resolver necesidades técnicas; la dinámica de interacción dirigida a la realización de las piezas musicales en el estudio de grabación permitió la realización de la observación participante en tanto quefue en ese contexto donde se pudieron evidenciar las condiciones, potencialidades y capitales culturales aplicados al desarrollo de la tarea común.

El segundo escenario lo constituyó la comuna 15; en tal espacio se realizaron entrevistas a los miembros en el ámbito de sus hogares y el colegio. A partir de las 


\section{perifèria}

Número 20 (2) diciembre, 2015

revistes.uab.cat/periferia

entrevistas se pudieron reconocer rasgos socio-demográficos circunscritos en la historia de los barrios y las lógicas de la subordinación socialque aqueja a los jóvenes en elDistrito Especial de Aguablanca.

El crecimiento de la ciudad de Cali, que se incrementó en la segunda mitad de siglo $X X$, generó una separación de la ciudad en sentidos sur y oriente. En el sur se asentaron los dueños de las haciendas quienes tiempo después modernizarían sus predios y le darían rostro a lo que hoy es la ciudad. En el oriente tuvieron lugar asentamientos irregulares producto de la llegada de inmigrantes provenientes fundamentalmente dela Costa Pacífica colombiana; la aparición de invasiones promovidas por intereses políticos populistas dio origen a lo que se reconoce como el Distrito Especial de Aguablanca, compuesto por las comunas 13, 14 y 15.

Mientras elsur contó con políticas mínimas de planificación,el oriente creció de forma desordenada generando lo que Vásquez (2001) denominó "las dos ciudades"; dos espaciosdivididos por una avenidaprincipaldonde se fomenta la desigualdad y opresión propias de las relaciones entre grupos establecidos (del sur) y grupos marginados (del oriente).

Debido a que Aguablanca está constituido en su mayoría por inmigrantes afrodescendientes, los grupos del sector encuentran en la valoración de sus tradiciones autóctonas una manera para participar en el espacio público yproponer, desde las expresiones artísticas de sus comunidades de origen, estrategias de integración socialpara afrontar los efectos sociopolíticos de la marginación que han padecido.

Para el caso de los jóvenes que participaron en la investigación resulta importante estudiar cómo su relación con las expresiones artísticas de su comunidad los ha hecho críticos y distantes del conflicto juvenil violento materializado a través de la violencia entrepandillas. Los jóvenes que integraron la investigación estudian en los colegios del sector, participan activamente en los grupos de reflexión política afrodescendiente y se identifican como actores activos del desarrollo de su comunidad. Eneste sentido, uno de los criterios por los cuales se escogieron aestos grupos tenía que ver con el aparente éxito que tuvo en la socialización de estos jóvenes el paso por las instituciones educativas. Dicho de otra forma: el hecho de 


\section{perifèria}

Número 20 (2) diciembre, 2015

revistes.uab.cat/periferia

que estuviesen escolarizados y que participasen en los grupos de la comunidades un hecho que distade otras posibilidades que tienen los jóvenes del sector y que están asociadas con el desprecio padecido en el contexto institucional y familiar.

El siguiente artículo presenta una reflexión inscrita en el marco de los estudios culturales y propone una vía de interpretación para la relación entre consumo cultural, capital cultural y creación musical juvenil en el caso de jóvenes habitantes de la comuna 15. El trabajo de campo que soporta la discusión categorial se realizó siguiendo las consignas de la Investigación Acción Participativa (IAP) las cuales fomentan un desempeño activo del investigador en los procesos que desarrollan los sujetos participantes del ejercicio investigativo, de esta forma tanto investigador como participantes pueden trabajar en el desarrollo de tareas concretas que dan cuenta del entramado de relaciones sociales (Ander-Egg, 2003).

Para la consolidación del diseño metodológico IAP se plantearon tres actividades, en el marco de los dos escenarios anteriormente descritos, que buscaban develar el potencial de la acción juvenil evidenciado en la producción musical. La primera actividad consistía en la ejecución de talleres conducentes a la planeación de acciones para la intervención cultural de los espacios públicos de la comuna 15. La segunda actividad estuvoorientada a la producción de un producto musical desarrollado en un estudio de sonido profesional. En la tercera actividad se realizóuna estrategia para visibilizar el grupo a través de la realización de un videoclip, un documental audiovisual y presentaciones musicales en eventos de la Pontificia Universidad Javeriana Cali. Todos los registros y los productos derivados de la experiencia IAP fueron almacenados en la página web titulada Sin Fronteras ${ }^{2}$; se sugiere al lector de este texto que consulte la hipermedia adjuntapuesto que ahí están compilados los diferentes productos derivados de la experiencia investigativa.

Para la interpretación de la experiencia de investigación se emplearon categorías de análisis en las cuales se presenta el consumo cultural como proceso sociocultural

\footnotetext{
${ }^{2}$ Página web Sin Fronteras: http://proyectos.javerianacali.edu.co/proyectocomuna15/index.html
} 


\section{perifèria}

Número 20 (2) diciembre, 2015

revistes.uab.cat/periferia

antes que como intercambio económico;también se alude a la categoría de capital cultural y a los estudios realizados sobre el uso de los espacios públicos y los medios de comunicación por parte de jóvenesen América Latina. De esta manera se proponen tres instancias de argumentación que permiten el desarrollo de la discusión: (1) El consumo cultural como camino para pensar lo propio y lo común; (2) Entre la familia y la escuela: consecución del capital cultural; y (3) participación social y creación musical juvenil.

\section{El consumo cultural como espacio para pensar lo propio y lo común}

El consumo es comprendido desde su racionalidad económica, esto debido a que desde algunas perspectivas de las Ciencias Sociales el consumo es considerado como un período del ciclo de producción y reproducción social donde se genera una expansión del capital y se reproduce la fuerza de trabajo (García Canclini, 1995). Desde este punto de vista, las necesidades y los gustos individuales no determinan la acción de consumir, todo depende de la manera en que el sujeto se inserta en la lógica social entendiendo el consumo como contenido del intercambio económico.

Desde la Antropología se han realizado estudios que plantean cómo el encuentro entre culturas supone el uso de estrategias para la construcción de un contexto común con cierto grado de estabilidad que halla en el consumo un escenario de reciprocidadadecuado (Krischke Leitão, Nogueira de Oliveira, \& Pinheiro Machado, 2006: 125). Los jóvenes que participaron en la investigación aluden a referencias ubicadas en el plano del consumo cultural; asumiendo que tales experiencias son vividas por todos independientemente de las condiciones económicas de quienes interactúan; de esta forma tales vivencias se convierten en ejemplos de exaltación y de descripción de lo que se desea llegar a ser. Al respecto el siguiente testimonio representa la postura de uno de los jóvenes respecto de las aficiones y gustos a los que se puede acceder en la comuna 15 :

Me encanta la música de Juanes, me encanta la música de ese man. Eso es como parte de Pop y en parte del Hip-hop, hay alguien que yo desde que lo escuché yo dije "yo quisiera ser como ese man"; Es un man que se llama Porta, 


\section{perifèria}

Número 20 (2) diciembre, 2015

revistes.uab.cat/periferia

él es español y yo creo que todas las canciones de él son buenas, no hay una de las canciones de él que sean malas, no que yo conozca. (David, 20 años)

El encuentro entre productores y consumidores constituye unaescena de socialización en el cual se genera un lenguaje para elesclarecimiento que ofrece el sujeto sobre sus gustos. Para García Canclini (1995) se trata de una "racionalidad sociopolítica interactiva", puesto que tal racionalidad exige un individuo capaz de pensar según los parámetros de una educación donde elementos como las tecnologías, las modas y el reconocimiento social se expresan como dispositivos que promulgan esta forma de relación como la más real y efectiva. De esta forma, el consumo es unazona donde los conflictos originados por la desigual participación en la estructura productiva se continúan a propósito de la distribución y apropiación de los bienes de la cultura (Castells, 2013).

Desde esta perspectiva, el consumo es considerado como el territoriodonde se discute por lo que produce la sociedad y por las maneras de usar aquello que genera tal producción. En consecuencia se admite el carácter interactivo del consumo y se observa su relevancia en la vida cotidiana en tanto que no se trata de un comportamiento compulsivo e irracional, se trata de uno de los modos de interacción humana más reconociblesen las sociedades contemporáneas.

García Canclini alude a cómo esta forma de ver el consumo ha ayudado a que los movimientos políticos no se queden estancados sólo en la dimensión de las luchas laborales, sino que también consoliden movilizaciones que tengan que ver con la apropiación y significación de los bienes, puesto que el aumento del consumo representa el aumento del poder adquisitivo y por ello es un indicador de los conflictos sindicales. Para Tourain (2013), los movimientos sociales actuales se caracterizan por proponer estrategias de inclusión cultural en escenarios democráticos existentes; ya no existe la pretensión ideológica de cambiar el diseño básico de la sociedad, pero si de demandar condiciones para la supervivencia de los grupos y los horizontes de mundo que los caracterizan. 


\section{perifèria}

Número 20 (2) diciembre, 2015

\section{revistes.uab.cat/periferia}

Es posible considerar el consumo como un proceso socio-cultural que posibilita las formas de uso, apropiación y significado de los bienes de la cultura sujetos a intercambio entre individuos y grupos que ofrecen un punto de vista sobre cómo debería ser la sociedad. A través del consumo se tramitan manifestaciones de clase que logran resolverse gracias al valor simbólico que se le atribuye a los bienes; un ejemplo de tal idea, extractado de la experiencia etnográfica, lo constituye el fenómeno de la piratería de las marcas donde el valor de los bienes muchas veces no está constituido desde la calidad intrínseca de los productos sino desde la reputación de su marca; así, comprar la misma marca en el circuito de la piratería responde, por un lado, a la racionalidad económica de lo más barato; pero, por el otro, a la posibilidad de poder competir a través de los símbolos de la distinción con aquellos actores sociales con las condiciones económicas para pagar el precio original deaquello que los va a distinguir.

Según la experiencia etnográfica, los jóvenes que participaron de la investigación viven en un contexto subordinado y hacen parte de familias que han padecido la pobreza y la falta de oportunidades en materia de educación y trabajo. Los atuendos que usan para el encuentro con los investigadores y las presentaciones musicales son adquiridos en las tiendas de ropa donde se piratean las marcas y cuyas prendas se venden a un menor valor. Es evidente que los jóvenes no pueden acceder a bienes costosos, pero a través del acceso que brinda la piratería logran insertarse en la sociedad de consumo al aprender e imitar los símbolos que utilizan otros jóvenes con mejores posibilidades económicas.

En este orden de ideas, es posible plantear que el consumo puede entenderse como el lugar de la distinción y la diferenciación entre grupos sociales puesto que es ahí donde se gesta la racionalidad del intercambio. Por ello el consumo no se resuelve exclusivamente desde la posibilidad de acceso a los bienes de la cultura, sino también a la capacidad que tienen los sujetos para interpretar los símbolos que se usan para dicho intercambio.

En los productos de comunicación realizados por los jóvenes se evidencia un esfuerzo por interpretar los símbolos de la cultura del consumo de la ciudad de Cali; 


\section{perifèria}

Número 20 (2) diciembre, 2015

revistes.uab.cat/periferia

si se escuchan las canciones producidas [asequibles a través de la página web Sin Fronteras] se pueden encontrar referencias comunes que aluden a la experiencia juvenil de Cali y no exclusivamente la de los sectores marginados del Distrito Especial de Aguablanca. En otras palabras: se ha usado el lenguaje del consumo cultural para proponer un punto de vista sobre lo que es ser joven en Cali. Sobre este asunto el siguiente testimonio:

¿Crees que tu música integra a los jóvenes de la ciudad? Pues sí, porque nosotros los jóvenes siempre buscamos la forma de expresar como nosotros los jóvenes vivimos. Muchas veces cuando un joven la escucha y toda la cosa y se siente identificado con esas canciones, entonces es una forma en la cual nosotrosnos integramos a ellos, expresando como lo que nosotros vivimos, que también es lo que ellos viven. (Jonathan, 18 años).

Otra cualidad del consumo es la capacidad de generar integración. Los participantes de la investigación utilizaron diferentes recursos para diferenciarse de otros jóvenes y ofrecer una apreciación propia sobre la vida social; también se expresó la necesidad de participar en procesos de integración juvenil más complejos y que vayan más allá de las tensiones entre los grupos subordinados y hegemónicos; en otras palabras: integrar una colectividad donde los orígenes socio-económicos no condicionen las formas de cooperación.

Para García Canclini (1995) no es suficiente diferenciarse porque la sociedad no funciona como una lucha de facciones; es preciso generar condiciones para el encuentro y eso se logra a través de los símbolos que legitiman procesos de comunicación. "El consumo se presenta como recurso de diferenciación, pero constituye, al mismo tiempo, un sistema de significados comprensibles tanto para los incluidos como para los excluidos" (García Canclini, 2006: 84). De ahí que si los miembros de una sociedad no compartieran los sentidos asignados a los bienes, no serviría de nada la posesión de dichos bienes para establecer diferenciación.

El escenario del consumo cultural evidencia una dialéctica que fluctúa entre lo propio (la distinción) y lo común (la integración). Esta tensión dimensiona los 


\section{perifèria}

Número 20 (2) diciembre, 2015

revistes.uab.cat/periferia

procesos de identificación mediante los cuales los jóvenes se formulan una idea sobre lo que son y lo que desean llegar a ser. El esfuerzo por expresar las búsquedas existenciales a través de un lenguaje de lo juvenil alusivo a la alegría, la extroversión y las relaciones solidarias pueden comprenderse como una consecuencia de la interiorización del consumo cultural como mecanismo de comprensión de la realidad social de lo que es ser joven. Al respecto un entrevistado plantea: "Yo creo que a través de mi música me trato de plasmar así como soy yo así como loquito, como alegre, como caribeño, sí. Así que los ritmos o mis letras tratan de plasmar lo que soy yo, autentico, tal y como soy sin inventar". (Junior, 17 años).

En síntesis, el consumo cultural ha sido una primera estación para pensar las condiciones de producción que subyacen a la creación musical juvenil. Considerando la dialéctica de lo propio y lo común, como tensión generadora de lenguajes sobre lo juvenil, resulta importante pensar sobre el contenido de las producciones en tanto que éstas reflejan un ideal normativo sobre lo que se es y se desea llegar a ser tomando distancia de los problemas sociales que se viven en medio de la pobreza y la subordinación. Las piezas de comunicación realizadas en el marco de la investigación IAP respetaron las decisiones que tomaron los jóvenes respecto del modo en que éstas contribuirían a la presentación de ideas sobre sí mismos; resultaron interesantes las conversaciones sobre las expectativas relacionadas con una carrera musical y la vida artística en general, asuntos que en términos de igualdad social no son posibles para la mayoría de jóvenes del Distrito Especial de Aguablanca.

\section{Entre la familia y la escuela: consecución del capital cultural}

Según Bourdieu (1988), el capital cultural supone una síntesis de la socialización efectuada en la familia y la institucionalización educativa. Respecto del trasegar del sujeto por la educación, es preciso considerar que la escuela constituye la transición del orden de lo familiar a la esfera pública; el papel de la escuela es el de 


\section{perifèria}

Número 20 (2) diciembre, 2015

revistes.uab.cat/periferia

normalizar los conocimientos derivados de la relación entre el individuo y la sociedad; tal proceso produce marcas identitarias sobre las cuales se generan formas de distinción y exclusión, todas estas compatibles con la inserción del individuo en la sociedad.

Para Bourdieu la adscripción del individuo a la sociedad depende (1) del habitus cultural, (2) el acceso alos bienes culturales, y (3) la adquisición de títulos académicos. Esta integración homogeniza las experiencias sociales al tiempo en que estandariza los bienes de la cultura que luego entraran a convertirse en una expresión de la subjetividad del individuo y de los grupos en el espacio simbólico del consumo cultural.

El habitus cultural se constituye en el espacio intersticial generado entre la familia y la escuela; en tal espacio se establece familiaridad con referentes que serán decisivos en la adopción de gustos. Los bienes culturales son aquellos que se heredan o se consiguen en el marco de esa relación [familia-escuela]. El habitus brinda la posibilidad de "establecer una relación inteligible y necesaria entre unas prácticas y una situación en la que el propio habitus produce el sentido con arreglo a categorías de percepción y apreciación producidas a su vez por una condición objetivamente perceptible" (Bourdieu, 1988, p, 99).

Para Bourdieu (1988), los gustos individuales no están necesariamente definidos por las propiedades que poseen en un determinado tiempo o en las condiciones que se instauran en el habitus, tal definición ocurre en la relación entre la capacidad de acceso y el uso social de los bienes culturales; dicho de otra forma: las posibilidades de posesión de bienes culturales, así como su viabilidad desuuso, son lo que determina la consolidación del habitus.

La posesión de títulos académicos garantiza formalmente una competencia específica puesto que asegura la posesión de una cultura general, extensa y prestigiosa. Sin embargo las diferencias que construyen las clasificaciones escolares tienden a reforzar diferencias reales centradas en las creencias reconocidas al 


\section{perifèria}

Número 20 (2) diciembre, 2015

revistes.uab.cat/periferia

momento de diferenciar conductas destinadas a la aproximación del ser real y el ser oficial (Bourdieu, 1988).

Para este caso de estudio es preciso resaltar tres características del capital cultural que lo relacionan con lo que se ha planteado sobre el consumo cultural. En primer lugar, esta noción da cuenta del lugar que tiene la tensión entre el individuo y el grupo y la manera en que se justifica la acumulación de bienes culturales. En segundo lugar, la relación entre familia e institución educativa permite situar el ámbito del consumo cultural juvenil y dimensionar el lugar que ocupa el ocio y el tiempo libre en la concreción de gustos. Y, en tercer lugar, la adquisición del capital cultural es compatible con los procesos de identificación juvenil que también tienen lugar en el consumo cultural.

En síntesis, la relación entre el habitus, los bienes culturales y la titulación académica posibilitan la comprensión de la expresión juvenil situada en el ámbito de la familia y la escuela. No obstante, para los jóvenes que viven en contextos marginados, realidades como la violencia intrafamiliar y la deserción escolar son sólo dos de los grandes problemas causados por las limitaciones que causa la opresión social. Esto no significa que no exista un anhelo de experimentar estas experiencias socializadoras, lo que sucede es que se han consolidado otras estrategias afianzadas en el ideal de lo tradicional y lo autóctono para justificar la manera en que se accede al ámbito de los bienes culturales. Las subcategorías emergentes del espacio familia-escuela sirven también para pensar lo que sucede con la expresión juvenil cuando las circunstancias sociales no son favorables. Al respecto el siguiente relato:

Mi vocación como músico nació aquí en el Centro Cultural, porque la verdad yo en el momento en que cumplí mi mayoría de edad no estaba estudiando, me fui a prestar servicio militar, salí y no sabía que rumbo tomar. Y pues gracias a Dios, viene a dar aquí en el Centro Cultural y desde ahí me nació como eso de "Uy bácano la música, me llama la atención". Es la manera de yo expresar algo que siento y que quisiera que escucharan otras personas. (David, 20 años). 


\section{perifèria}

Número 20 (2) diciembre, 2015

revistes.uab.cat/periferia

Los participantes en la investigación IAP eran en su mayoría jóvenes afrocolombianos de familias provenientes de los departamento del Chocó, Nariño, Cauca y Valle; el acceso a la música fue posible gracias al encuentro intergeneracional en sus familias y comunidades de origen. De los 25 jóvenes que estuvieron en el proceso, 14 aprendieron a tocar un instrumento por sus propios medios; la totalidad estaba escolarizada. Si bien la educación pública del Distrito Especial de Aguablanca dista de ser la mejor, los jóvenes participantes planteaban un discurso en el que se idealizaban sus tradiciones culturales para completar los déficits de su formación educativa.

¿Dónde aprendí mi oficio de músico? Pues no sé, responderé lo que me dice mi papá. Mi papá dice que cuando yo era muy pequeño, pues ellos me llevaban a la iglesia y entonces estaba la batería de la iglesia y que yo gateaba y que yo me iba hacia la batería y gateando chiquitico yo cogía los palos y obvio empezaba a darle a los Tones, a los platillos, a lo que viera y después fui creciendo ya quebraba los platos de la casa. Tuvieron que construir una batería de tarros de leche así sucesivamente. $Y$ así fui creciendo y sin que nadie me enseñara fui aprendiendo a tocar batería. (Junior, 17 años)

Sin embargo, el recurso de la exaltación de lo propio es limitado dado que en algún momento los jóvenes de Aguablanca tendrán que competir con jóvenes de otras procedencias sociales donde la relación con las instituciones educativas es mejor. Siguiendo la perspectiva de Bourdieu, para los jóvenes de otras procedencias sociales las oportunidades serán distintas ya que cuentan con respaldos institucionales que certifican su educación. Esto constituye un problema de fondo en lo que refiere a las condiciones de igualdad para el acceso al mercado laboral y la participación social en contextos másamplios y democráticos.

\section{Participación social y creación musical juvenil}

Lo que se ha podido evidenciar hasta este punto es que la relación entre consumo cultural, capital cultural y creación musical juvenil se circunscribe en el contexto del habitus cultural; espacio que reproduce la conflictividad social pero que genera las 


\section{perifèria}

Número 20 (2) diciembre, 2015

revistes.uab.cat/periferia

condiciones para la integración y la aparición de los gustos. En este plano del análisis surge el papel mediador de los medios de comunicación parala consolidación de estéticas y formas de clasificar el capital cultural. Para Woodsite \& Jiménez (2012), la música y la televisión tienen un papel relevante en la construcción de las identidades juveniles en tanto que es a través de esos medios que se legitiman narrativas de éxito que inciden en la valoración social de los grupos. Según los autores, son los medios de comunicación los que se encargan de la consolidación de meta-relatos, mitos y rituales sociales donde se ponen en evidencia perspectivas de ordenamiento social, valores morales y propuestas para el modelamiento de la subjetividad. Al respecto el siguiente testimonio:

Si usted no sale en un medio de comunicación, es muy complicado que usted se dé a conocer. Entonces si usted tiene un contacto, haga lo que sea. Tiene que buscarse algo que lo deje ver, que lo muestre a usted como artista. Y pues para uno, el más importante medio de comunicación es la televisión. Cuando usted sale en televisión usted, iUy no!, es grande. Entonces toca escucharlo porque desde que sale en la televisión es porque es bueno. (David, 20 años).

Para Muñoz (2002) el papel de los medios en la configuración de los atributos de las juventudes constituye una fuente de trabajo derivada de la lectura de los consumos culturales entendidos como origen y finalidad de las creaciones juveniles. Los procesos de creación agenciados por jóvenes se circunscriben en el habitus cultural pero también en el carácter utópico y fantasioso asociado con la representación de la vida de los artistas que es reproducida y ponderada por los medios de comunicación.

En la investigación desarrollada el fantaseo en torno a los medios de comunicación y una posible inclusión a ellos, por medio de la grabación de piezas discográficas en un estudio profesional desencadeno expectativas poco realistas sobre los resultados de la investigación. A pesar de que siempre se explicaron los alcances académicos del trabajo, los jóvenes asumieron que participar les permitiría ingresar a otros espacios de la creación musical que siempre les han sido negados. 


\section{perifèria}

Número 20 (2) diciembre, 2015

revistes.uab.cat/periferia

(...) para mí es una puerta que se abre, como a todos. En algún momento que a uno le toque decir: "ve mirá que yo soy artista, yo soy autor de música entonces me gustaría que me escucharan", que uno fuera a otro estudio y lleguen digan: "pero ah dame una muestra", y uno, " mirá este trabajo lo hice con la Universidad Javeriana, esa letra la hice yo". Eso es una puerta, son puertas que se abren y pues la Universidad Javeriana metió mucho en eso y para mí es un gusto haber participado en esto y ojalá seguir participandoy esperar que viene más adelante. (David, 20 años).

El fantaseo hace parte de la constitución psíquica de los jóvenes adolescentes y también es un elemento a considerar en el momento de plantear que las identidades juveniles también pueden ser estudiadas con la rigurosidad que caracteriza los estudios antropológicos sobre los grupos étnicamente diferenciados. Tal como lo propone Krotz (2002), la utopía también puede constituir una pregunta para la antropología, dado que ésta tiene lugar en las expectativas que produce el encuentro intercultural. Dicho de otra manera: las expectativas de reconocimiento intersubjetivo y las posibilidades de participación en la sociedadpuedan también ser pensadascientíficamente; de estos procesos pueden derivarse expresiones políticas que nos advierten del modo en que los grupos juveniles perciben la sociedad que habitan.

El debate tiende a complejizarse cuando se contrasta el potencial político de los jóvenes versus la eficacia transformativa de sus movilizaciones. El estudio de Feixa, Sánchez \& Nofre (2014) demuestra que las expresiones juveniles tienen un potencial renovador debido a que articulan a sus consignas políticas información proveniente de fuentes que para otras generaciones no estaban disponibles. La comprensión de los grupos juveniles y su expresividad exige entender el consumo cultural como una síntesis de las diferentes fuentes de conocimiento social que antes no era conciliables. Para grupos de otras generaciones el marxismo nada tenía que ver con la moda y la cultura popular; en la actualidadtales elementos parecen mezclados en una retóricaa la que aluden los jóvenes para expresar públicamente lo que piensan de su generación y las luchas sociales que les interesan. 


\section{perifèria}

Número 20 (2) diciembre, 2015

revistes.uab.cat/periferia

En este sentido, la alusión a la moda y la cultura popular como contenidos y fuentes de inspiración para la creación juvenil suponen también una manera de controvertir un mundo caracterizado por la crisis de la ideología y la parálisis de la crítica social (Honneth, 2009). De este modo, "la construcción de identidades sociales desde la moda hace parte de un proceso de lucha y conflicto entre modelos sociales e ideologías opuestas que se juega también en los tableros de la política partidista y los estilos empresariales" (Muñoz, 2002: 200). En este orden de ideas, los contextos educativos proporcionan espacios para la diversificación de estas formas de ser en tanto que padres y profesores se convierten en el referente represor y corrector de las subjetividades juveniles. Al respecto el siguiente relato:

A los adultos los veo como eso, como adultos. Como gente que ya vivió y que tienen más experiencia, que tienen más cosas que contarle a uno. En el Distrito los jóvenes como que no se comen ese cuento y ellos quieren ser los que cuenten las historias, los que les digan a los adultos que tienen que hacer. Los pelaitos [niños] ahoritica están metidos en una película HD con gafas y pues ellos ya son los que son y nada y los adultos no tienen que decir nada. Los adultos tienen que estar callados y pues la verdad. Pero los adultos son eso, autoridad pues para eso ya vivieron más que uno y uno es un pelao. (Junior, 17 años).

Según Muñoz los años ochenta representaron valores conservadores que no pudieron contener las expresiones culturales masivas de artistas tales como Michael Jackson, Prince, Boy George y un sin número de grupos rockeros que pusieron en cuestión tabúes relacionados con la sexualidad, el género y la sociabilidad. "Cyndi Lauper, reveló que la dureza tiene voz femenina, mientras que Pee Wee Herman deleitó audiencias con sus infantilismos, rompió con décadas de sofisticación estirada, madurez y respetabilidad, posicionando la simpleza o al menos el derecho a la diferencia" (Muñoz, 2002: 201). En consonancia con estos fenómenos de la cultura popular se empezaron a erigir diversas formas de expresiones juveniles que proponían rupturas respecto de los valores hegemónicos de la sociedad de los adultos. "La cultura juvenil fue en parte, una auténtica respuesta a esta situación, un área de símbolos y significaciones comunes, compartidos en parte o en su 


\section{perifèria}

Número 20 (2) diciembre, 2015

revistes.uab.cat/periferia

totalidad por una generación, y donde procesaron no solo las naturales tensiones de la adolescencia, sino la especificidad de ser joven en este momento social (Muñoz, 2002: 201).

En la actualidad, la cultura juvenil convoca expresiones contradictorias que se perciben propias pero al mismo tiempo manufacturadas por las industrias culturales de siempre pero que en la actualidad cuentan con mayores recursos de difusión. Ya no es adecuado hablar de los medios de comunicación de masas [prensa, radio, televisión], sino de la sociedad masiva de expresión [Internet], sociedad en la que los consumidores de mensajes también pueden producirlos y expresarse sobre todo y como quieran (Rincón, 2012). Según uno de los entrevistados:

Yo creo que el principal medio es el Internet, lo que es youtube.com. En ese lugar está toda la música que uno quiere buscar. Por decir yo voy donde un compañero y se va a meter en Internet me dice "parce [amigo] cuando usted quiera venga que aquí le descargamos toda la música que usted quiera". Y sí, yo creo que por más $C D$ [reproductor de discos compactos] o por más cosas que nosotros tengamos, yo creo que mi principal medio es ese. (David, 20 años).

Los jóvenes del Distrito Especial de Aguablanca no son distintos a otros jóvenes que escuchan el llamado de la sociedad masiva de expresión. Las fantasías relacionadas con ser artistas y superar los conflictos sociales de sus comunidades a través de la música hacen parte del tipo de consignas que direccionan la experiencia del creador musical juvenil. En este medio la producción cultural abre el espacio para el encuentro entre jóvenes y las posibilidades de colaboración, procesos que desdibujan las fronteras impuestas por la historia de opresión que caracteriza el sector.

En coherencia con lo expuesto, García Canclini \& Urteaga señalan que para el análisis de las "relaciones colaborativas y vínculos de apoyo entre generaciones, el caso más claro es el de los jóvenes músicos y otros agentes involucrados en la producción musical alternativa" (García Canclini \& Urteaga, 2011, p, 132). El estudio de los jóvenes músicos es a su vez un pretexto para reconocer el uso de 


\section{perifèria}

Número 20 (2) diciembre, 2015

revistes.uab.cat/periferia

tecnologías de la información y la comunicación para la reproducción y distribución de contenidos culturales que dan cuenta del ensanchamiento de los repertorios políticos que caracterizan el espacio juvenil actual.

Sobre este asunto, García Canclini \& Urteaga (2011) plantean que los movimientos juveniles siguen teniendo líderes y apuestas estéticas conducidas exclusivamente por museos, medios, agencias de publicidad, disqueras y las industrias culturales que han monopolizado el mercado de la creación. Si bien las tecnologías de la información y la comunicación generan una ilusión de participación democrática, dicho proceso no es ajeno a las formas de subordinación donde ya no es necesario tener una presencia física de quien subordina, sino que existe un sistema sin rostro que ofrece lógicas de marginamiento donde el acceso a los capitales culturales depende de las posibilidades sociales con las que cuenten los jóvenes. Afirma Cruces que "la oportunidad de participar en ellas [las industrias culturales] está desigualmente compartida, la concentran y manejan quienes disponen de saberes, idiomas y posiciones socioeconómicas, o sea capitales culturales necesarios para posicionarse competitivamente" (Cruces citado por Canclini \& Urteaga, 2011, p, 134).

\section{A modo de conclusión}

Conforme con lo expuesto, este artículo ofrece una perspectiva sobre la relación entre consumo cultural, capital cultural y creación musical juvenil en el marco de una investigación IAP. Se han extractado relatos que permiten situar la información proveniente de la experiencia etnográfica en el nivel de la descripción inspirada en los conceptos desarrollados en el marco de los estudios culturales sobre músicas y producción expresiva juvenil.

Como elementos a discutir resulta conveniente valorar el potencial político de la expresión juvenil de habitantes de un sector marginado que ven en la creación musical una ruta para alejarse de las dificultades de su contexto. Los lógicos de la vulnerabilidad social inciden en las expectativas de reconocimiento que tienen los jóvenes respecto de lo que es posible en el contexto barrial.La experiencia 


\section{perifèria}

Número 20 (2) diciembre, 2015

revistes.uab.cat/periferia

etnográfica nos ha enseñadoque las instituciones sociales, tales como la familia y el colegio, son escenarios de valoración grupaldonde los jóvenes participan activamente desde la aprehensión odimensionamiento de un lenguaje propio para explicar la vida en común en el ámbito de la diversidad y la violencia.

La ruta de interpretación propuesta permite aproximarnos el papel de los jóvenes productores de música y su importancia para la discusión sobre la convivencia en la comuna 15.Se estima que la comprensión de las condiciones de producción de las músicasde la comunidad ayudaa ensanchar el espacio en que se definen o discutenasuntos atinentes a la resolución del conflicto juvenil violento en el Distrito Especial de Aguablanca. Tal preocupación resulta pertinente toda vez que la pregunta sobre qué hacer con los jóvenes de los barrios marginales constituye un vacío preocupante de las políticas públicas de la ciudad de Cali.

La descripción del proceso de participación social de los jóvenes a través del consumo cultural, el capital cultural y la creación musical permite ubicar las fantasías o utopías como elementos de comprensión de la otredad cultural. Al facilitar las condiciones de producción y proponer una metodología IAP para el acompañamiento del grupo, se produjo un encuentro a partir de expectativas generadas por el tipo de tareas a realizar. De esta forma, los estereotipos sobre los artistas y sus posibilidades de trascendencia empezaron a fundamentar una manera de nombrar la experiencia de trabajo. Se concluye que desde ese lugar, el de otorgar sentido a las fantasías, también se puede estudiar a un grupo desde una perspectiva antropológica.

Dicho de otra forma: las expectativas de reconocimiento expresadas en los relatos evidencian una manera de comprender la vulnerabilidad social y presentar los reclamos de inclusión ante una sociedad que se percibe distante y ajena. A través de la reflexión sobre la producción cultural podemos dimensionar una gama de registros desde donde es posible pensar en clave antropológica la generación de las estructuras estamentales juvenilesy sus modos de expresión. 


\section{perifèria}

Número 20 (2) diciembre, 2015

revistes.uab.cat/periferia

Finalmente, lo que se ha propuesto es una manera de comprender una experiencia IAP. En ese sentido, se ha obrado de forma tal que el andamiaje teórico pueda ser flexible respecto de la riqueza experiencial y del modo en que los participantes han forjado una narrativa sobre la convivencia en la comuna 15.La experiencia sirvió para pensar en las capacidades de producción cuando se poseen los recursos de producción;en este caso, el estudio de grabación se convirtió en escenario de intercambio y diálogo de saberes entre jóvenes de distintas procedencias sociales; tal experiencia permitió consolidareltrabajo discográfico titulado Gracias.

\section{Bibliografía}

Ander-Egg, E. (2003). Repensando la Investigación-Acción Participativa. Argentina: Grupo editorial Lumen Hvmanitas.

Castells, M. (2013). Redes de indignación y esperanza. Madrid: Editorial Alianza Editores. DOI: 2.6418676

Castro Domingo, P., \& Rodríguez Castillo, L. (2009). Antropología de los procesos políticos y del poder. Ateridades, 107-127.

Feixa Pàmpols, C., Sánchez García, J., \& Nofre Mateo, J. (2014). Del altermundialismo a la indignación Cronotopos del activismo político juvenil en Barcelona. Nueva Sociedad No 251, 87-99.

García Canclin, N., Castro, N., \& Poso, U. (3 de julio de 2015). Cultura y desarrollo una visión distinta desde los jóvenes. Obtenido de http://www.fundacioncarolina.es/wp-content/uploads/2014/08/AI65.pdf

García Canclini, N. (1995). Consumidores y ciudadanos. México: Editorial Grijalbo. DOI: 4.9313474

García Canclini, N. (2006). El consumo cultural una propuesta teórica de Néstor García Canclini. En G. Sunkel, El consumo cultural en América Latina (págs. 82-90). Bogotá: Editorial Andrés Bello. 


\section{revista de recerca i formació en antropologia}

\section{perifèria}

Número 20 (2) diciembre, 2015

revistes.uab.cat/periferia

Honneth, A. (2009). Crítica del agravio moral. Patologías de la sociedad contemporánea. Buenos Aires: Fondo de Cultura Económica de Argentina, S.A.

Krischke Leitão, D., Nogueira de Oliveira, D., \& Pinheiro Machado, L. R. (2006). Antropología \& Consumo. Porto Alegre, RS, Brasil: Editora AGE Ltda.

Krotz, E. (2002). La otredad cultural entre utopía y ciencia - un estudio sobre el origen, el desarrollo y la reorientación de la antropología. México: Fondo de Cultura Económica.

Martin Barbero, J., Bonilla, J., Rincón, O., Zuluaga, J., \& Cataño, M. (2012). De las audiencias Contemplativas a los productores conectados. Cali: Sello Javeriano.

Muñoz González, G. (2002). Consumos culturales y nuevas sensibilidades. En H. Cubides, M. Laverde Toscano, C. Valderrama, \& M. Mario, "Viviendo a toda" Jóvenes, territorios culturales y nuevas Sensibilidades (págs. 194-240). Bogotá: Siglo del Hombre Editores.

Touraine, A. (2013). ¿Podremos vivir juntos? Barcelona: Fondo de cultura económica.

Vásquez, E. (2001). Historia de Cali en el siglo 20. Cali: Artes gráficas del Valle.

Woodsite, J., \& Jiménez, C. (2012). El campo musical: actores y redes. En N. García Canclini, F. Cruces, \& M. Castro, Jóvenes culturas urbanas y redes digitales (págs. 96-98). Barcelona: Editorial Ariel. 


\section{perifèria}

Número 20 (2) diciembre, 2015

revistes.uab.cat/periferia 